\title{
Healing processes following tooth extraction in orthodontic cases
}

\author{
N. Cohen ${ }^{1}$, J. Cohen-Lévy ${ }^{2}$ \\ 1 DDS, PhD University Lecturer, Paris 7 University, Private Practice at 10 rue Margueritte, \\ 75017 Paris \\ 2 DDS, PhD Former University Hospital Dental Assistant of the Hospitals of Paris, \\ Private Practice at 255 rue Saint-Honoré, 75001 Paris
}

\begin{abstract}
This article reviews the normal and pathological healing processes that take place after tooth extraction in orthodontic cases, and their associated complications within the mucosa or alveolar socket, such as gingival clefts or bone defects. The general and local factors that are involved in such deficient healing cases are detailed, in parallel to surgical procedure to enhance ridge preservation or to 'regenerate' tissues. The relationships between the orthodontist and periodontist are underlined, because both praticioners assess patient's risk factors and follow him during this treatment stage.
\end{abstract}

\section{KEY WORDS}

Dental extraction, atraumatic extraction, healing, alveolar socket, bone regeneration techniques, graft

\section{INTRODUCTION}

Extraction is a procedure that is currently performed in orthodontics, either in the context of early treatment (serial extractions, germectomies), for adolescents with severe crowding or protrusion/overjet, or for adult patients who have fewer possibilities for expanding the arch.

The consequences of this "simple" procedure have not always been accurately assessed, whereas many mucosal and osseous complications may show up after the extraction: bone resorption with collapse of the alveolar process, a gingival cleft or gingival recession in the area surrounding the extraction site. Besides the potential esthetic repercussions, these periodontal defects also give rise to a clinical problem with achieving some orthodontic movements, such as complete closure of the space or uprighting a root.

Each individual has his own capacity to heal, that is determined by his biotype and biological profile, consisting of cytokines and inflammation mediators 4,5,14,25,29,49,52. The various processes involved may additionally be altered by ageing, or by a 
general illness. The potential for local healing also depends on acquired factors, and especially by the cause of the extraction (following trauma, endodontic lesion, periodontal lesion or on the contrary extraction of a healthy tooth for orthodontic purposes).

This article provides a bibliographical review on normal and pathological post-extractional healing and on the distinctive characteristics of extractions in orthodontics, followed by a presentation of the techniques that allow for preservation (atraumatic extractions) or osteomucosal regeneration (grafts, biomaterials and membranes).

while blood fills in the empty socket. This creates a platelet aggregation that forms a clot (erythrocytes and leukocytes embedded in a fibrin gel). The clot controls the bleeding, but also serves as a support to the successive stages of cicatrization. The platelets produce growth factors and mediators (cytokines) involved in angiogenesis, the Platelet-DerivedGrowth-Factor (PDGF) and the Transforming-Growth-Factor-beta (TGF- $\beta$ ). The PDGF is linked to the attraction of the neutrophils and the macrophages, and influences the activity of the smooth muscles and the mitogenic properties of the fibroblasts. The TGF- $\beta$ also signals the attraction of the macrophages, that stimulates them to secrete cytokines such as the Fibroblast-Growth-Factor (FGH), the PDGF, the Tumor Necrosis Factor- $\alpha$ (TNF- $\beta$ ), and interleukin-1 (IL-1).

The dental socket is next rapidly colonized by granulation tissue, consisting of neo-vascular tissues, inflammatory cells and erythrocytes, that virtually replace the entire clot within a week. The next stage is called the provisional matrix, where the mesenchymal cells are organized 


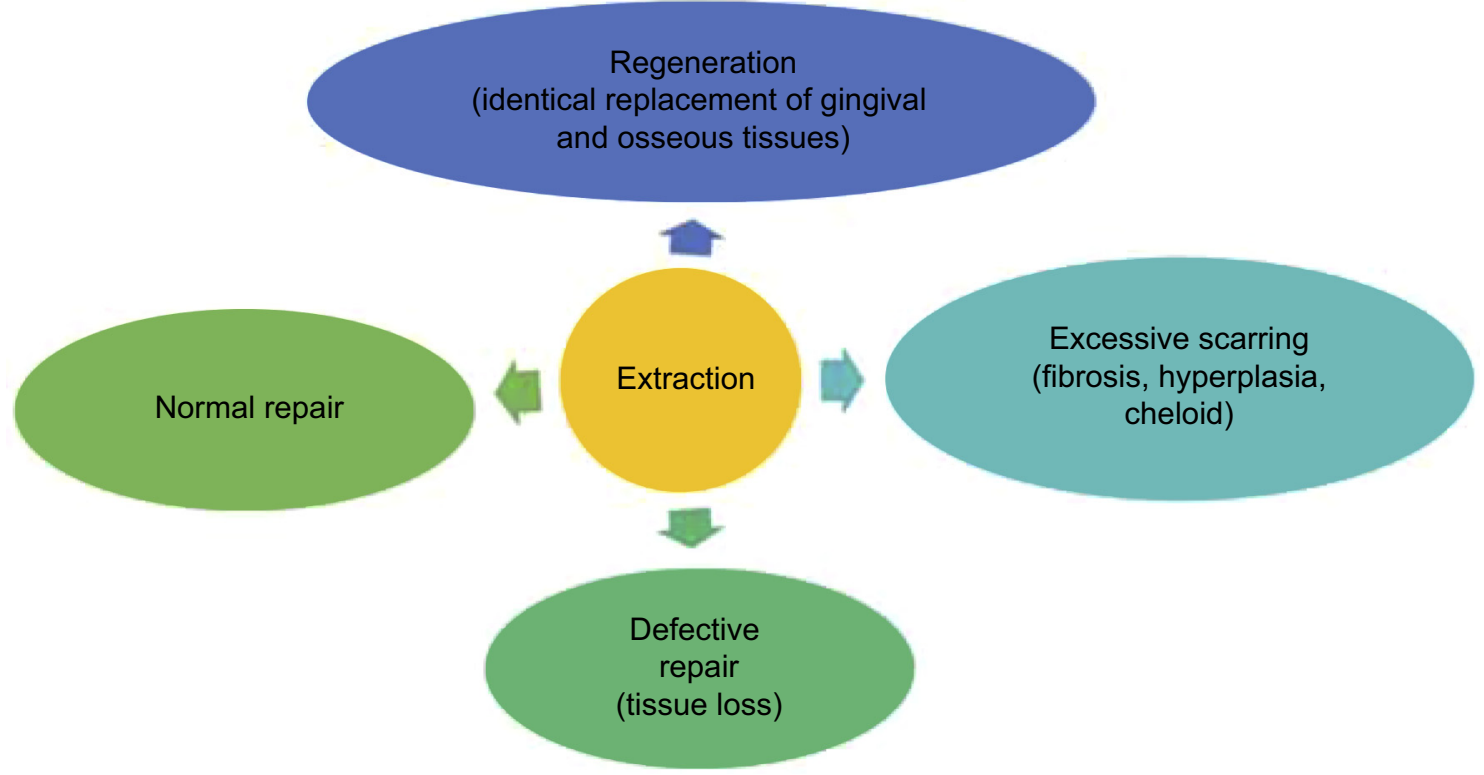

Figure 1

Types of post-extractional healing: normal healing, pathological and procedure-assisted techniques for regeneration.

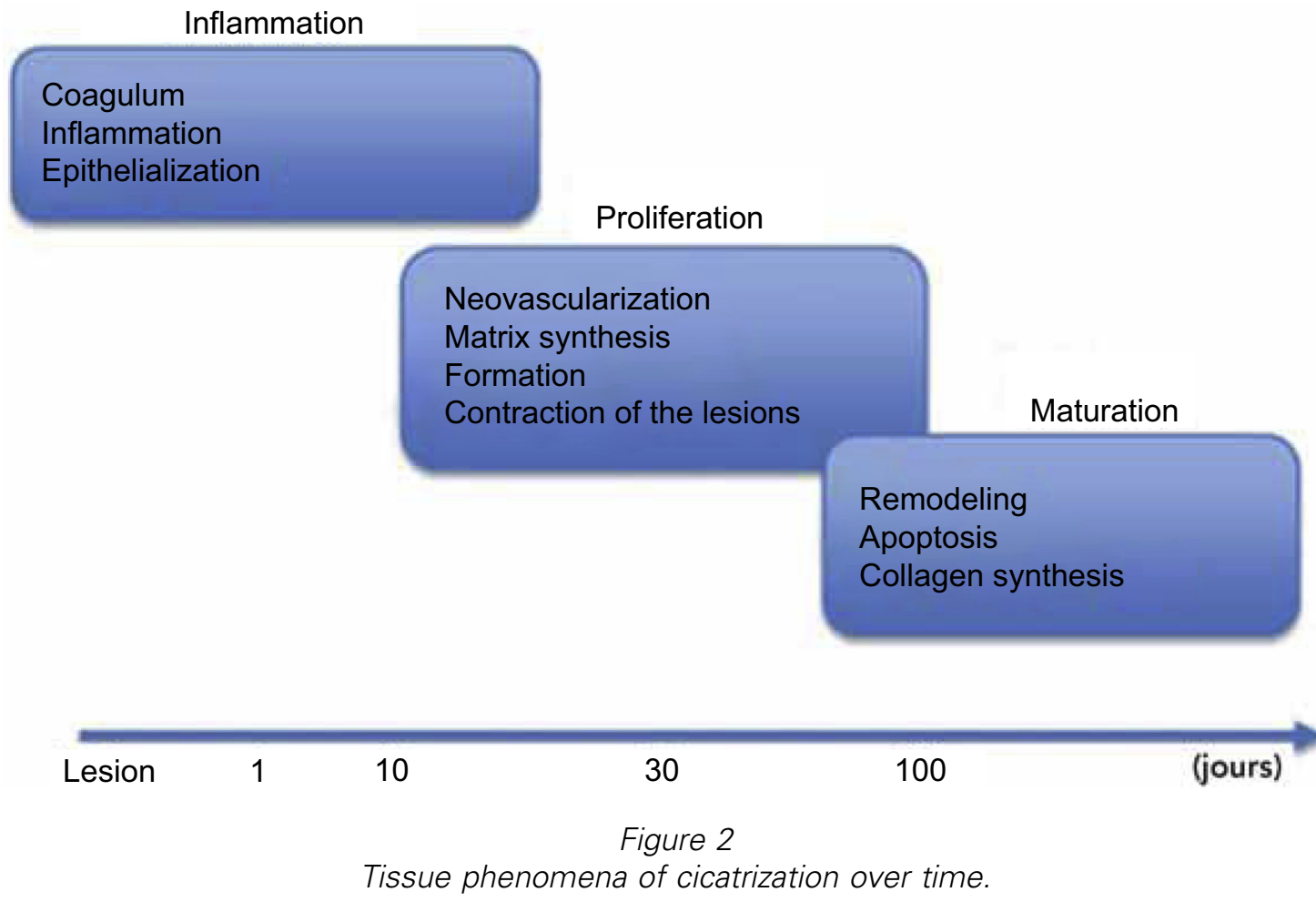


into a dense network, within the collagen fibers and the vessels; the mineralization progressively begins, that resembles the fingerlike formation of immature bone within the matrix, embedded in "primary spongy cell culture". This immature bone is progressively remodeled into trabecular bone and spongy bone (trabeculae of mineralized bone, with secondary osteons, surrounded by medular spaces rich in vessels, adipocytes, mesenchymal and inflammatory cells).

Human studies on post-extractional healing have demonstrated that mineralization begins at the end of the first week; between the $2^{\text {nd }}$ and $4^{\text {th }}$ week, the bony appearance of the clot has disappeared, with the proliferation of granulation tissue and the provisional matrix; and between 6 and 8 weeks, most of the granulation tissue has been replaced by the provisional matrix (approximately $60 \%$ ) and with immature bone (approximately $40 \%$ along the outer walls of the alveolus). The osseous formation has not been completed 24 weeks after extraction.

The dynamics of post-extractional healing depend on the mucous tissues and underlying bone tissue whose cells do not regenerate at the same rate. The principles of periodontal regeneration were established on the basis of this principle.

The principle of guided tissue regeneration (GTR), developped by Nyman in $1987^{38}$, is based on the principle of selective recolonization of the detoxified radicular surfaces, by preventing, with the help of a membrane (resorbable or not), the invasion of the site by epithelial and connective cells. This allows for cementogenesis when teeth are present and osteogenesis when they are not. This osteogenesis can only take place if the osteoblasts have time to form a bony network and if osteogenesis is not inhibited by contact with the fibroblasts. The need to "filter" the cells that penetrate into the zone of regeneration must not however impede the expression of the inflammatory factors since they are required for healing.

\section{Mucosal healing}

The epithelialization of the extraction site is founded on the migration and division of the cells of the basal stratum, starting from the areas bordering the wound. It begins within 12 hours following surgery. The healing is distinctive in the buccal cavity since it is a septic and humid site with a very high rate of regeneration. The speed of the mucosal healing has therefore been compared to that of the skin, and seems to be faster, due to certain biological factors, whose production varies with the individual and the site under consideration.

Several studies, initiated by the research of Graves et al., on healing in mice, have shown the the IL-1 was essential for buccal healing but not for that of the $\operatorname{skin}^{21}$. Similarly, the expression of the the TGF- $\beta$ appears to modulate the ability to heal in the buccal cavity due to its chemotactic properties $^{16,59}$. Given that these mediators are expressed differently based on the individual, it is conceivable that they will be good markers 
in the future for assessing the risk for defective healing.

Since we still have no predictive test to date for inflammatory mediators involved in healing, clinicians switched to clinical and macroscopic correlations. The pre-surgical evaluation of soft tissues is especially important, because the periodontal typology provides some basis for prognosis. Today it is recognized that a fine biotype is a surgical risk factor; manipulating soft tissues poses a risk and their capacity to heal and to regenerate seem to be reduced due to the small amount of underlying connective tissue.

\section{Bone healing}

In most situations, an extraction induces bone resorption, that is always more significant on the buccal $\operatorname{side}^{2,4,12,25,52}$. This resorption leads to a reduction in vertical height of the ridge ${ }^{53}$ and a lingual displacement of its axis ${ }^{4,5}$.

However, regardless of the surgical technique used, a loss of volume in the transverse and vertical direction is evident ${ }^{22,49}$. The systematic review of Hammerle et al. ${ }^{22}$ calculates the horizontal loss to be $3.8 \mathrm{~mm}$ and the alveolar height to be $1.24 \mathrm{~mm}$ six months after extraction. A number of authors have then suggested that we perform, in cases of tri-dimensional loss, bone regeneration procedures $3,20,32,50,55,60$, and they describe the implementation of membranes to avoid collapse of the ridge ${ }^{17,43}$, the use of grafts of autogenous bone, allografts 20,60 or xenografts ${ }^{3,7,12}$. These studies were conducted before implant restoration, therefore, their conclusions cannot be extrapolated to orthodontic treatment today.

In the clinical case presented in figure 3 (a to j), the female patient, 23 years of age who benefitted from an orthodontic treatment that involved extraction of premolars, presented with a vertical fracture of a permanent first molar, that needed to be extracted. The intraoral clinical views at 8 weeks post extraction (Fig. 3 a, b) and photos of the flap while it was trimmed (Fig. 3 c) clearly show the failure of the healing and the tridimensional loss of volume, in a patient who was however young, in good health and a non-smoker. Taking into account the prolapsed sinus and the low residual volume, we decided on a regenerative therapy including bone substitution material (Bio-Oss $^{\circledR}$, distributed by Geistlich ${ }^{\mathrm{TM}}$, Fig. $3 \mathrm{~d}$ ), placement of a membrane (Fig. 3 e and f). Protecting the membrane against the risk of exposure was ensured by sutures, ensuring a closure of the gingival edges without excessive traction (Fig. $3 \mathrm{~g}$ ). The sectional views (cone beam computerized tomography $\mathrm{CbCt}$ ) show the defective tridimensional bone healing before regeneration ( 8 weeks after extraction) (Fig. $3 \mathrm{~h}$ and i), and makes it possible to monitor the quality of healing (Fig. 3 h).

A systematic review conducted by Vittorini et al. ${ }^{56}$ analyzed the different techniques of extraction and of preservation of the dental socket in humans. They selected 424 scientific 


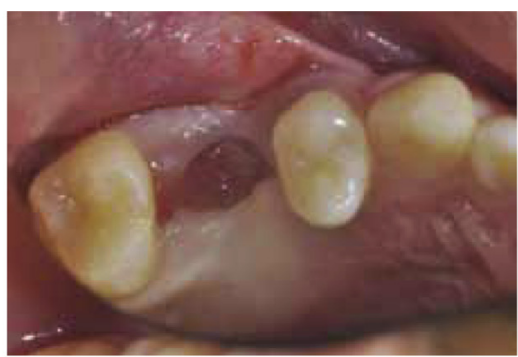

a

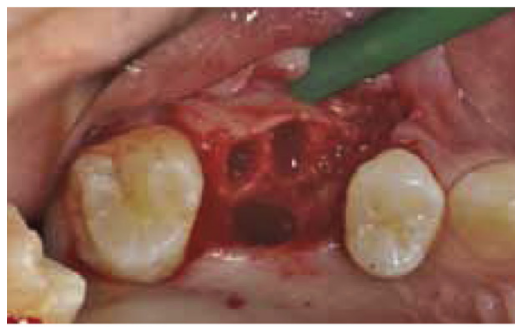

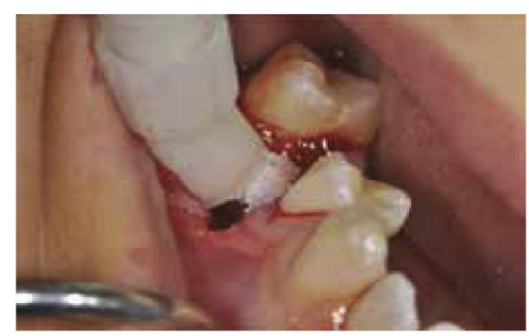

d

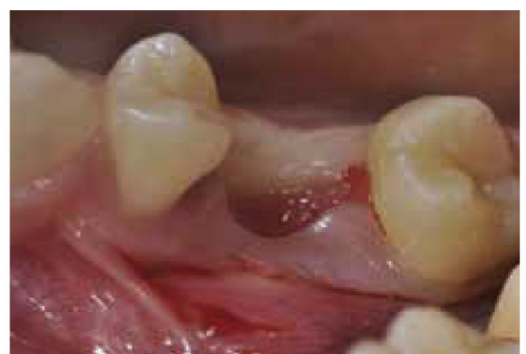

b

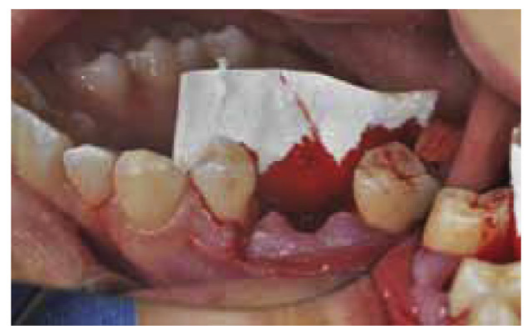

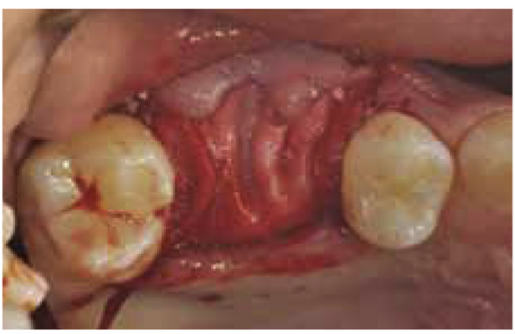

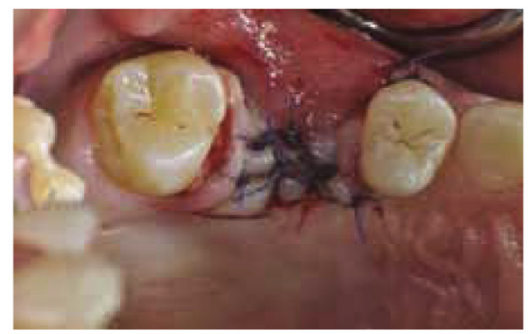

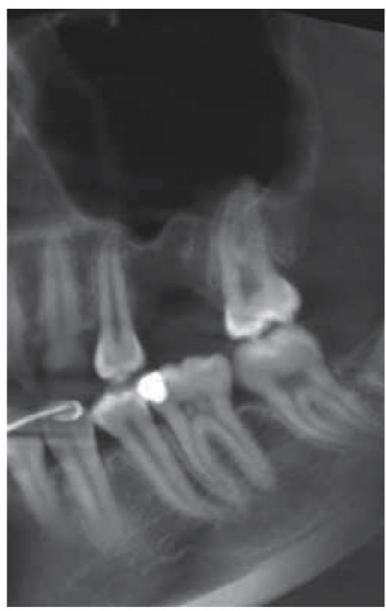

h

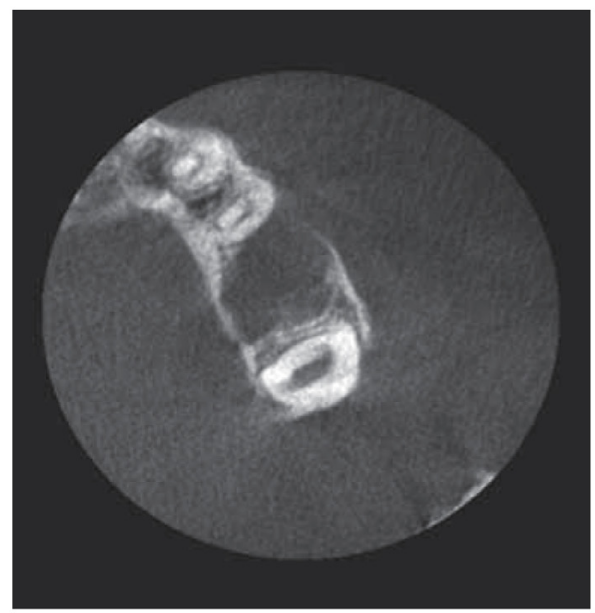

i

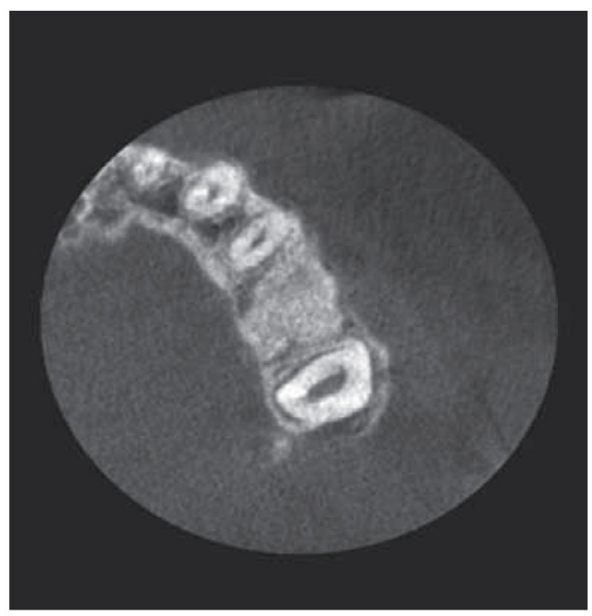

j

Figure 3

a) Occlusal view of the natural post-extractional healing of the patient after 8 weeks. b) Palatal view. c) Occlusal view after the the flap has been trimmed: lack of bone neoformation. d) Application of Bio-Oss ${ }^{T M}$. e) Application of a membrane (Bio-Guid ${ }^{T M}$ ). f) Final positioning and testing of the membrane. g) Sutures. h) Post-operative cone beam reconstruction. i) Axial cut of the same day examination. j) Immediate post-operative view. 
articles and compared the use with the non-use of post-extractional regenerative techniques. In every case, regeneration promoted the preservation of the bone volume. It was difficult to compare the various techniques that were used, but it seems that the implementation of a membrane may increase the quality of the healing. Manipulating the tissues (separating the flap or labial traction of the flap) appears to limit the loss of bone volume ${ }^{56}$.

\section{Pathological healing}

\section{Infectious complications}

Infectious complications can occur when the formation of coagulum does not take place or is altered by early fibrinolysis. They are caused by a bacterial colonization of the clot or by an inflammatory process entailing a massive migration of granulocytes. The relation between the operative trauma and the site infection has also been demonstrated and is attributed especially to exposing the bone too long during surgery, to drilling without irrigation, or to poor infection control ${ }^{6,23}$.

There can be simple, granulomatous and dry alveolitits, that present with pain two to four days after surgery. Another classification based on the the duration of healing ${ }^{27}$, includes alveolar osteititis, suppurative osteititis, necrotic osteititis and fibrous healing. With dry osteititis (or fibrinolytic or dry socket), the socket appears bare, with white greyish and bloodless walls ${ }^{39}$; with suppurative alveolitis, the blood clot is disorganized and purulant, typically with yellow greenish appearance. The pain is intense, and must be treated promptly.

Women are affected by infections significantly more frequently than men $^{15}$. This has shown to be related to the intake of oral contraceptives ${ }^{27}$.

Additionally, the frequency of alveolitis increases with age. They are rarely found in children, seemingly because there is better vascularization.

Smokers are more prone to infection $^{28,29}$. The operative technique and surgical instruments used for an osteotomy are also a factor. As a result of the use of drills fitted with an internal cooling system for osteotomies $^{30}$, infection complications appear less frequently. The experience of the surgeon, the use of a chlorhexidine mouthwash prior to the procedure ${ }^{11}$ might also have an impact on the frequency of infections.

\section{The use of antibiotics}

A recent Cochrane review evaluated 18 studies, with a total of 2,456 participants who received antibiotics (different types and dosages) or a placebo, immediately before or after extraction of the wisdom teeth. They concluded that there was enough scientific evidence showing that antibiotics administered just before and/ or after a surgical procedure reduced the risk for infection, pain and dry socket after extraction but that the 
use of antibiotics also triggers more secondary effects (generally brief and minor) in these patients ${ }^{34}$.

\section{Complications linked to taking medications}

All the drugs that are going to alter one of the physiological phases of healing are likely to expose patients to some complications (inflammatory phase and anti-inflammatory treatments, vascular and proliferative phase and anti-angiogenic treatments...).

Corticosteroids for example, administered systemically and in strong doses, delay healing. This affect is basically linked to their anti-inflammatory action (decrease of leukocyte migration, lymphocyte inhibition, decrease in macrophage phagocytosis, decrease in the production of antibodies and the appearance of antigens) and also related to the inhibiting action on fibroblastic proliferation, collagen synthesis and epithelialization. This delayed healing, with a more random regeneration phase, has been shown in vitro and in vivo 30 .

\section{Complications related to a pathological condition}

It is generally recognized that some patient profiles entail difficulties with healing. For example, patients with type 2 diabetes fall into this category. They present with the modifications of the expression of certain mediators such as TGF- $\beta$ that are essential for healing ${ }^{59}$. Controlling glycemia appears to be fundamental for normal healing, because hyperglycemia alters the leukocyte functions, decreases phagocytosis and chemiotactism, and increases the risk for infection. For these patients, healing can turn out to be very unpredictable.

For the case shown in figure $4 a$, the patient, 50 years of age, presents with type 2 diabetes, and with difficulty in controlling plaque, with severe maxillary crowding, 23 and 24 practically overlapped each other. He presented with chronic adult periodontitis with severe localized inflammation (Fig. 4 b). The orthodontic treatment plan chosen involved the extraction of 23, that presented with severe buccal recession. Healing occurred with invagination of the buccal mucosa, even though there was no orthodontic movement for closing the gap underway (Fig. 4 c.).

Patients with immuno-deficiency, whether they are infected with the human immuno-deficiency virus (HIV), have cancer or are taking immunosuppressive drugs, almost always systematically present with defective healing. With these patients, we observe a change in the quality of the inflammatory phase, a decrease in resistance to infections as well as the debridement of necrotic debris.

The lack of oxygenation or perfusion of tissues is also one of the main factors responsible for the delay in healing. In a hypoxic environment, the deposition of collagen on the matrix is initially slowed then interrupted if hypoxia continues. Therefore, patients who previously had oral radiation treatment or anti-angiogenic treatments are particularly at risk. The bone tissue when exposed to heavy doses of radiation undergoes irreversible changes with narrowing of the blood vessels, that then decrease the flow of blood to the tissues. 


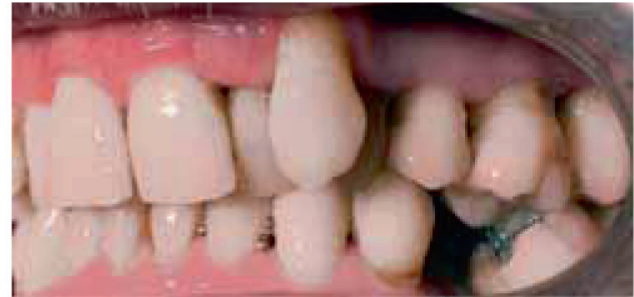

a

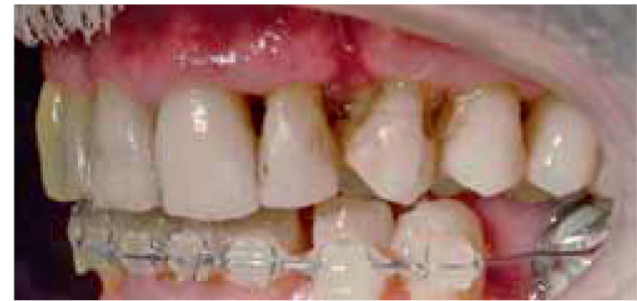

C

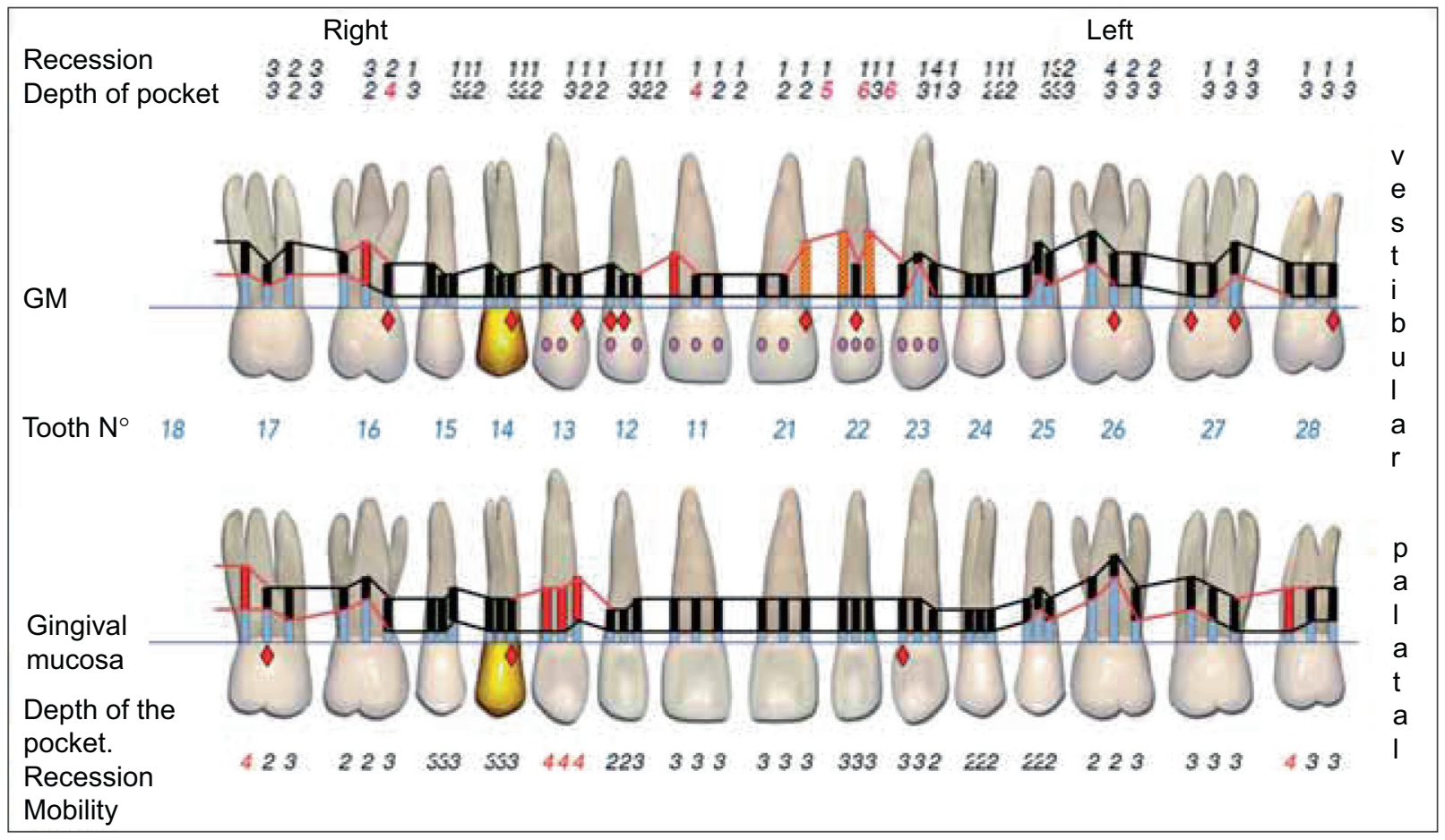

Figure 4

a) Lateral intraoral view of the patient before treatment, with ectopic 23, almost covering the entirety of the buccal face of 24. b) Periodontal probing of the patient. c) Healing during the course of orthodontic treatment (lingual technique on the maxillary, porcelain multi-bracket technique on the mandible).

\section{DISTINCTIVE CHARACTERISTICS OF ORTHODONTIC EXTRACTIONS}

\section{Extractions and alveolysis}

A recent study using cone beam computerized tomography (CbCt) compared the loss of bone support in a group of patients treated or not treated with extraction of the premolars $(n=12 \text { and } n=10 \text { respectively })^{35}$.
The patients presented with a Class II div. 1 malocclusion and were treated by the same practitioner, using the same technique. They were evaluated with $\mathrm{CbCt}$ before and after treatment, in order to determine the height of the alveolar ridge and the thickness of the bone in relation to 
the cemento-enamel junction. The authors found a decrease in the buccal-lingual alveolar dimensions in both groups, with no significant difference between them. On the other hand, the bone loss was significantly greater in the group treated with extractions, in the extraction site, and the distal region on the maxillary canines showed the most variation.

\section{Extraction and gingival clefts/ fissures $^{57}$}

The development of a gingival cleft on a site subjected to orthodontic space closure following extraction is a fairly common occurrence. Their frequency has been estimated to be $35 \%{ }^{45,46}$. In a study carried out by Robertson et al. ${ }^{46}$, forty patients treated with extraction of the premolars were examined in order to analyze the presence and distribution of gingival clefts, defined as an invagination of interproximal tissues with epithelial spikes (mesial and distal) of at least $1 \mathrm{~mm}$. Fourteen of the forty patients presented with cleft on one or several of the premolar extraction sites, while no cleft was evident in the premolar zones of the control group of patients i. e. patients treated without extractions.

Their etiology is still uncertain today. Some authors suggest that, for the affected sites, the transeptal fibers are disorganized and not regenerating ${ }^{57}$, since the invagination is developing passively by the folding of the gingival tissues; histological studies have demonstrated the presence of an epithelial hypoplasia, while the connective tissues present with a decrease in collagen and an increase in glycoaminoglycanes. Another hypothesis concerning the origin of these fissures is that there is a break in the gingival fibers, followed by a pathological bone remodeling with loss of the cortical bone ${ }^{42}$.

Gingival clefts are most frequently located on the buccal surfaces of the mandible (Fig. 5) and they appear to have clinical implications, that involve orthodontic relapse ${ }^{18}$ (reopening of the interdental gaps) as well as a increased difficulty in preserving healthy gums. The anatomical configuration of these gingival clefts contributes to the problem of cleaning the extraction site and predisposes the area to an increase in the plaque index. Therefore, it is recommended that the practitioner surgically treats these spaces and possibly use regeneration techniques ${ }^{42}$.

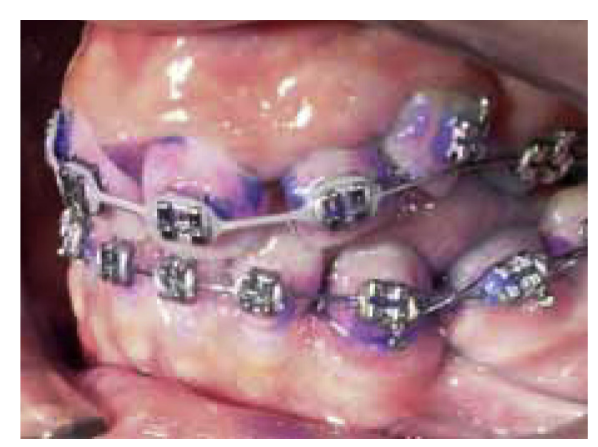

Figure 5

The development of severe gingival fissures on the mandible in this patient who underwent a planned extraction protocol, in the course of orthodontic levelling. The retraction of the canines has not yet been performed, but a lateral frenum seems to extend into the area of the gingival cleft. The color of the plaque clearly demonstrates that the patient hasn't mastered good tooth brushing techniques. 
The treatment of gingival clefts (without an osseous deficit) has been ascribed to the cold blade or the electric cautery: the incision begins apically at points marking the depth of the cleft and is directed coronally towards a point situated between the base of the cleft and the osseous crest. The osseous exposure is avoided at all costs, so that the incision attempts to recreate as much as possible an "ideal" gingival festoon. The excessive tissues are resected and a pack is applied to enhance healing.

In the case illustrated in figure 6 , an adolescent during the course of presurgical orthodontic treatment, that conventionally implies the extraction of the maxillary second premolars and of the mandibular first premolars, came in for treatment of this type of gingival cleft (Fig. 6 a, b and c), with a very inflammed periodontium and high plaque index. Following a cone beam xray (6 d, panoramic reconstructions, $6 \mathrm{e}$ axial cut and dentoaxial recontructions), it appears that the mucosal cleft has been complicated by mesial alveolar clefts on the first molars and severe root resorption, which will make the management and the prognosis for the adjacent teeth more difficult, even though the tooth vitality tests were positive.

A case report described the use of guided tissue regeneration for these cases of gingivo-osseous clefts after orthodontic closing of space ${ }^{42}$.

\section{Impact of the timing of orthodontic treatment following extraction}

Depending upon the author, the tooth adjacent to the extraction site may be moved into mature healing bone, or just the contrary, immediately following extraction, while the healing process is still underway. Based on the animal model, historical studies done by Bauerle ${ }^{8}$ and then Murphey $^{36}$ have reported a faster pace of healing in the bone in relation to the corresponding extraction site.

Araujo, in 2001, developed an animal model where he applied orthodontic forces on the teeth adjacent to the extraction site that was filled with Bio-Oss ${ }^{\circledR 1}$. He showed that the teeth could be moved three month after packing the socket, that new formations (resorption/apposition) could take place without affecting the quality of newly formed bone.

The authors emphatically insist on the need to adapt the therapy to the speed of resorption of the material and to its properties for remodeling, for angio-genesis, osteo-induction and osteo-conduction ${ }^{44}$. Cardaropoli et al. have shown the resorption capacity of this material after 14 days have passed ${ }^{13}$. These findings are still debatable and there seems to be agreement that the longer the movement is delayed, the lesser the risk ${ }^{44}$.

\section{Impact of the location of the extraction site}

The incisors have a thin buccal cortical bone, their roots may be prominent and sometimes outside of the osseous envelope (check to see if there were any prior orthodontic treatments to expand the shape of the arch); sometimes, when the 


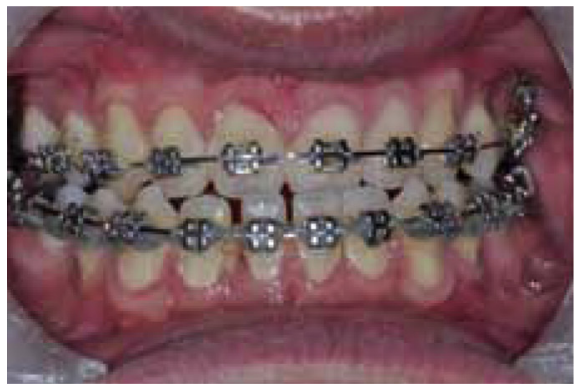

a

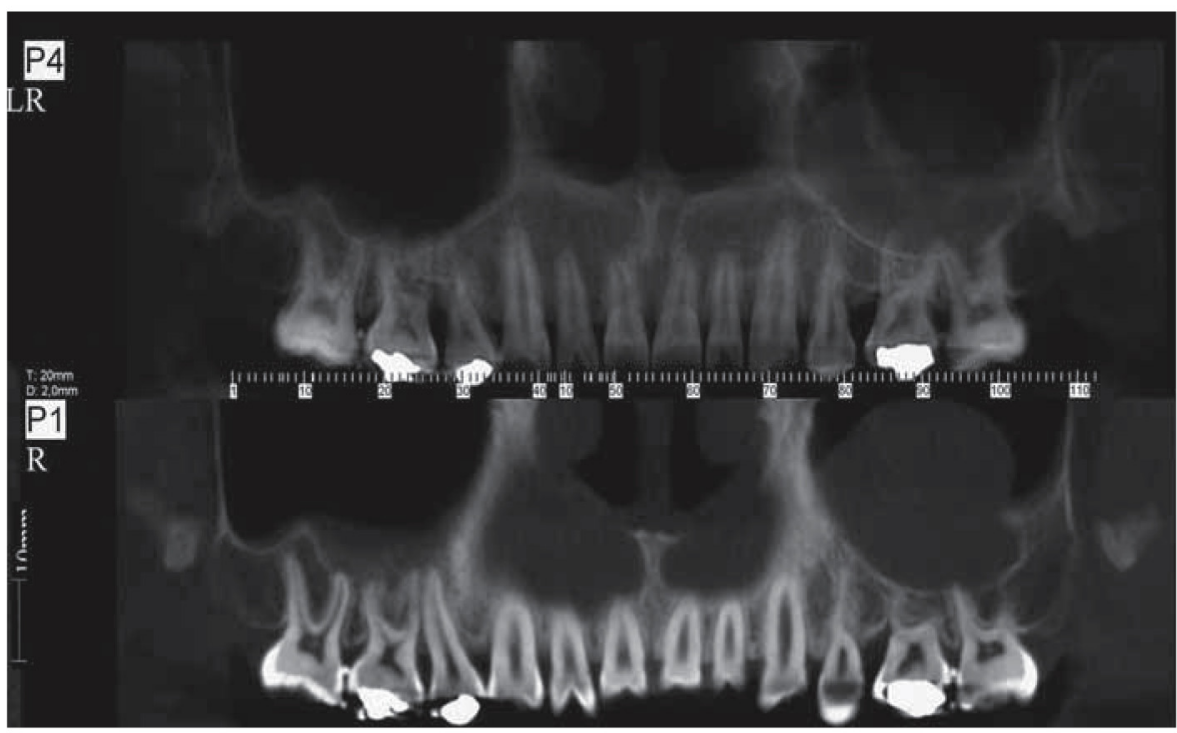

d
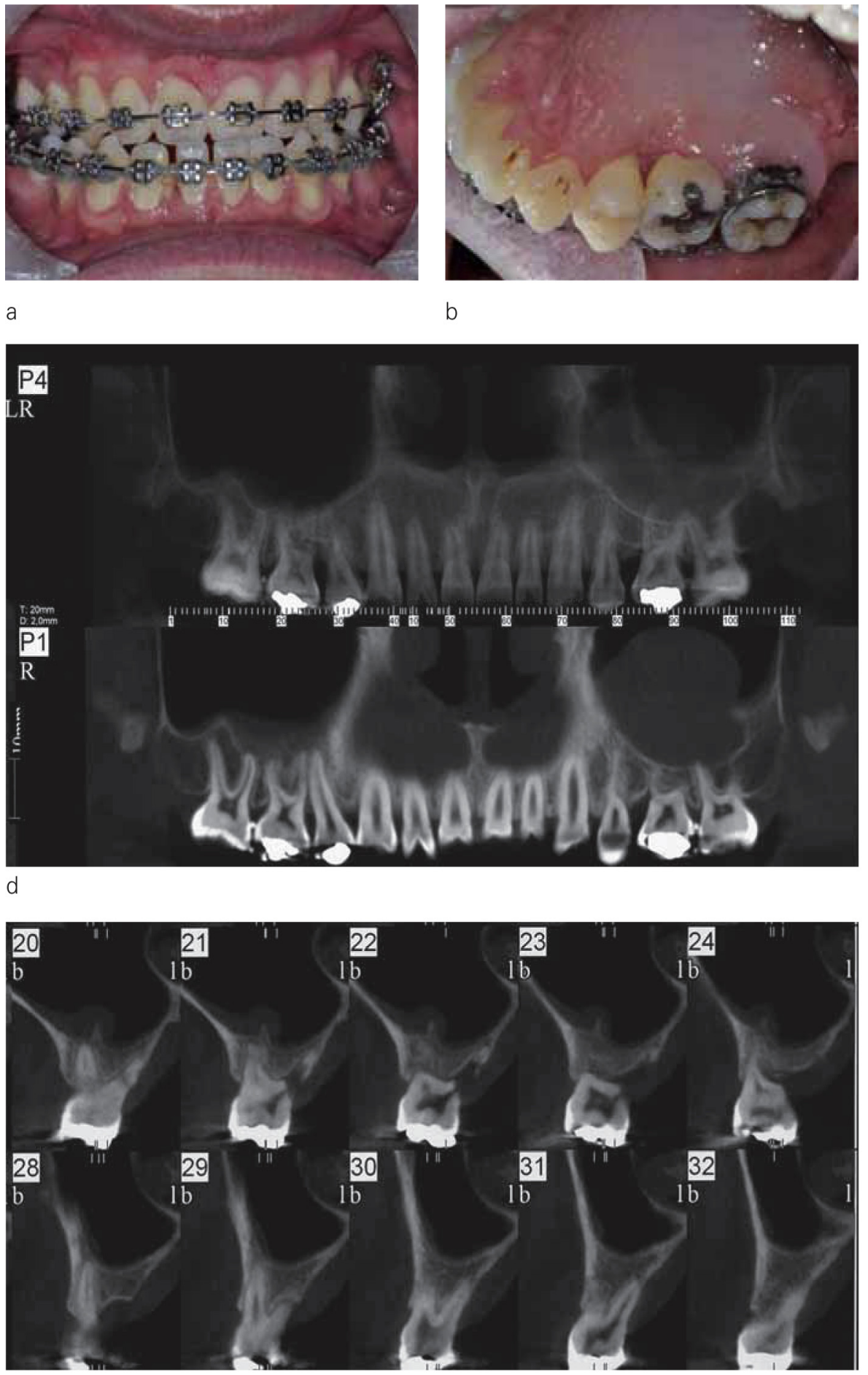

b

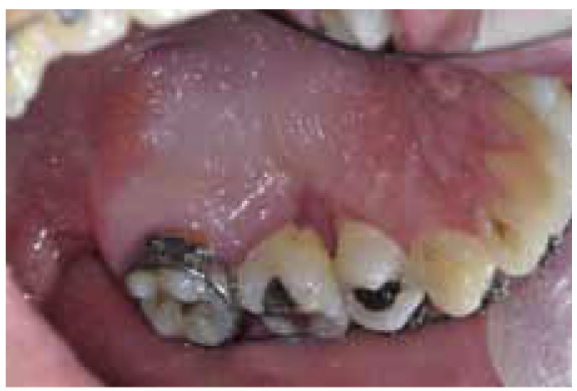

C

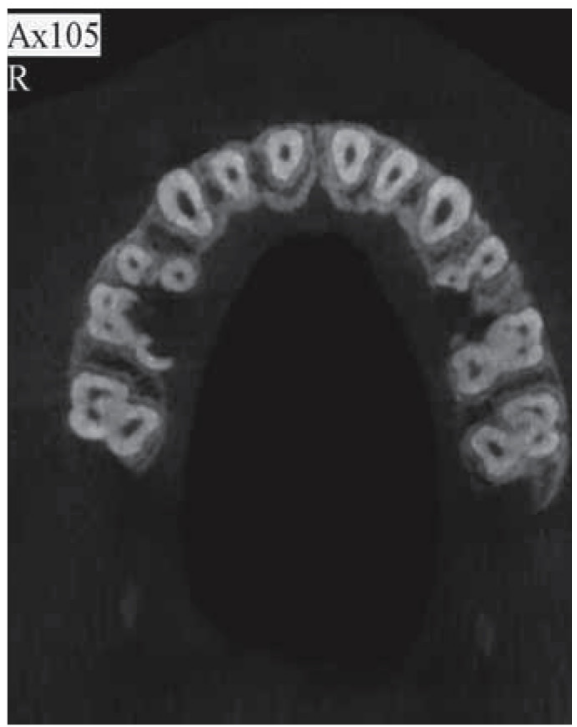

Figure 6

A patient presents with severe gingival clefts, complicated by alveolar clefts and root resorption after extraction of premolars. a) Frontal intraoral view, with calculus and plaque deposits and inflammation. b) Palatal view, the interdental gingiva appear edemic, purplish, with significant plaque deposits. c) The other side, similarly afflicted. d) Cone beam reconstruction. e) Axial cut showing the extent of the bilateral root and bone resorption. f) Dento-axial cuts: the palatal root of the first molars is almost completely resorbed. 
mandibular symphysis is narrow with significant lingual repositioning, lingual cortical bones may be, conversely, thinned out ("shaped like a comma").

The canines are the longest teeth in the arch, and the maxillary canines are the pillars of the face, and maintain close relations with the nasal fossa and the maxillary sinus, that they juxtapose. They are covered with a thin film of cortical bone, where fenestrations and dehiscences are generally present. Their extraction involves a significant risk for osseous collapse.

The maxillary premolars and molars, located close to the sinus, may for certain patients present a risk for oral sinus communication. With regard to mandibular premolars and molars that are located in less vascularized and thicker bone, the risk for infection complications is greater.

\section{Impact of a supracrestal gingival fibrotomy}

Various factors may affect the speed of the orthodontic movement, such as bone density, periodontal and osseous metabolism, or the applied force. Kaira et al. performed uilateral supracrestal fibrotomies in a group of 14 subjects, from 13 to 22 years of age, who were treated by the preprogrammed edgewise technique, and whose treatment was carried out with extractions on the maxillary and mandibular arches. The retraction was achieved with non-frictional mechanical force, using T-shaped loops, and each patient was his own witness (treated side/control side). The average difference measured $0.36 \mathrm{~mm}$ on the maxillary arch and $0.60 \mathrm{~mm}$ on the mandibular arch, but there was no clear evidence of any significant difference when a fibrotomy was performed ${ }^{26}$.

\section{ASSESSING THE POTENTIAL FOR INDIVIDUAL TISSUE REPAIR}

From the very first consultation, the various risk factors can be evaluated. Some factors are directly accessible, either with the medical history questionnaire that allows the practitioner to assess any possible alteration in overall healing process, or during the clinical examination (visual inspection, periodontal probing, xrays).

Other considerations, such as the biological factors for healing (inflammatory profile, cytokines...), are still not part of the diagnostic examination, but are particularly important for tissue repair.
Lang and Tonetti ${ }^{31}$ have synthesized the clinical factors by developing an assessment diagram for patients in periodontal maintenance. This diagram, presented as a "spider diagram", illustrated in figure 7 , is an easy to use visual aid for practitioner/ patient communication. It is useful for changing parameters, since some of them can be altered (smoking, plaque control). The role of the orthodontist is crucial for making the patient aware of the need to quit smoking before extraction and for reviewing a post-operative checklist. 


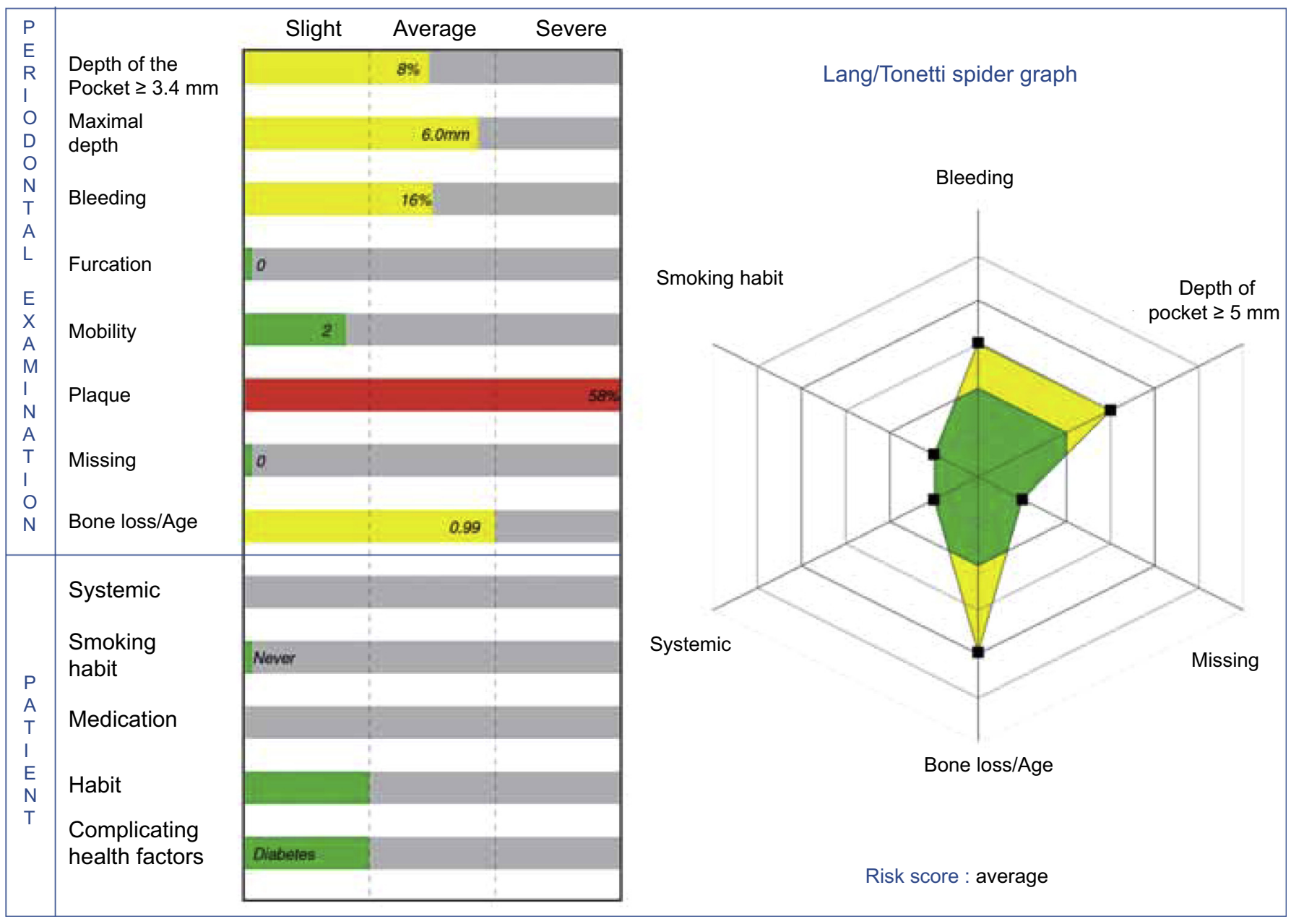

Figure 7

Lang and Tonetti spider graph, with the different vectors: bleeding when probed (bleeding), smoking (smoking habit), general and systemic factors (systemic), age and bone loss (bone loss/age), tooth loss (missing), deep pockets (depth > $5 \mathrm{~mm}$ ).

\section{General factors}

Healing for older patients is characterized by a decrease in the inflammatory response and in the proliferation of fibroblasts. A reduction in the synthesis of collagen, of angiogenesis and of epithelialization may be related to decrease in cellular capacity to produce and react to growth factors.
Actually, in animals, macrophage functions, the proliferation of the endothelial cells and the ability to proliferate and synthesize fibroblasts appears to diminish with age.

\section{Behavior of the patient}

The postoperative procession of a wound depends not only on care but 


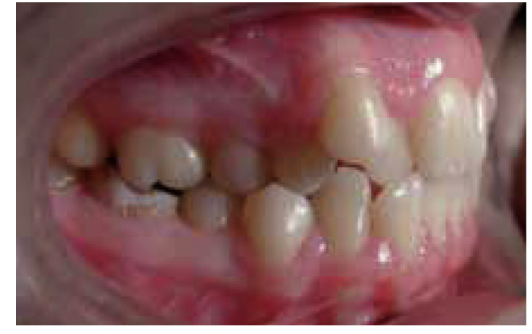

a

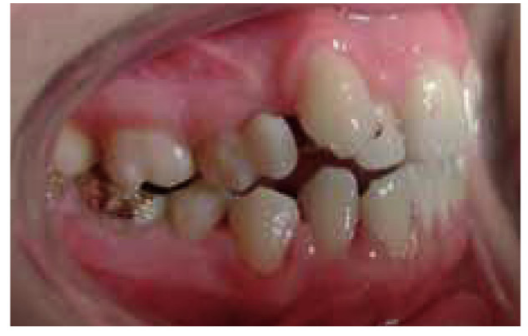

b

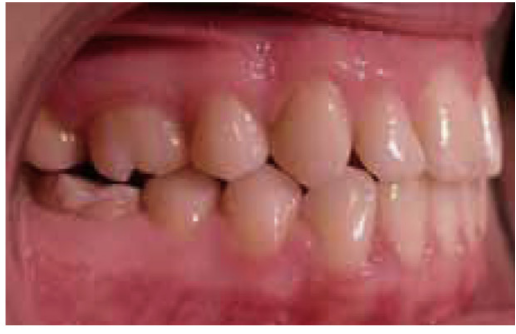

C

Figure 8

a) Case of a 25 year old patient treated with extraction of maxillary premolars, with the lingual technique (Incognito ${ }^{T M}$, 3M Unitek). b) The esthetic shell, made of composite materials and bonded on the proximal surfaces the second premolars, are not in contact with the mucosa thus making it possible to brush. c) End of treatment.

also on the behavior of the patient. Excessively rinsing the mouth on the day of the operation, tobacco or alcohol consumption (see supra), as well as exerting strenuous physical effort can lead to the loss of the coagulum and consequently infection.

\section{Plaque index}

The oral cavity is a septic healing environment, like the skin, that has both a positive and negative side: the presence of bacteria is a source of inflammation that can modulate the repair process by immediately recruiting specific effectors. However, excessive contamination of the wounds is a source of healing failure. Therefore, we recommend that when the orthodontist uses esthetic composite "shells", bonded to hide the extraction socket, so as not to press the shell against the mucosa and impede brushing that could promote the build-up of plaque and food deposits.

\section{Tobacco}

Smoking, that leads to both hypoxemia and hypoxia, is also responsible for healing failure. Nicotine produces vasoconstriction, increases the stickiness of plaque and the risk for mini strokes and ischemia.

If we take another look at the report from the French National Institute of Health $(\mathrm{HAS})^{24}$, it appears, accordingly to the panel of experts on perioperative smoking, "that the proven benefits of quitting smoking preoperatively vary based on how soon before surgery it stops: quitting 6 to 8 weeks before a procedure removes the risk of surgical complications due to smoking; 3 to 4 weeks before surgery, it improves the outcome for all parameters; even when it occurs 12 to 48 hours before surgery, it lowers the amount of carbon monoxide and enhances oxygenation. By continuing to abstain from smoking during the time required for healing (2-4 months) and possibly for bone consolidation improves surgical outcomes".

\section{Gingival biotype}

The concept of biotype was first described by Ollson and Lindhe ${ }^{40}$ who compared it to dental morphology. They differentiate a thin 
periodontal type, associated with a narrow and triangular coronal anatomy, from a thick periodontium that is associated with a wide and rounded coronal anatomy.

The profile of the gingival mucosa can be assessed directly: color, thickness, surface appearance, inflammatory condition of the marginal gingiva and mucosa.

The thickness of the gingival mucosa can be evaluated by the visibility of the periodontal probe and the transparency of the tissue when it is inserted into the sulcus ${ }^{28}$. From a surgical perspective, a fine biotype is even harder to manage since it is associated with dental malpositions, due to severely reduced interdental septa.

\section{Factors related to the surgical technique}

These techniques, developed for extraction protocols followed by immediate implants, known as atraumatic extractions ${ }^{47,58}$ are intended to preserve the alveolus and especially the buccal bone surfaces that are particuliarly thin on the anterior teeth. These techniques might possibly limit post-extractional bone resorption, and therefore prevent any change in the heights of the gingival collars when the prosthetic device is in place.

\section{Atraumatic extractions}

The principle behind atraumatic extractions is to pull the root on a vertical axis, and therefore avoid large movements during luxation.
A syndesmotomy is performed, then the root canal is prepared by using a bit with a smaller diameter than that of the auto thread-forming screws which are secondarily embedded into the canal. A wrench, manual or digital, makes it possible to regulate the torque force of the screw.

The screw is next connected to a metal cable and to a pulley system, that distributes the support on the entire half of the dental arch. A drawback of this system is that it can only be applied on monoradicular teeth, to straight roots (given the direction of the traction), with, for example, a risk for fracturing the apex of the lateral incisors that present with a thin apical distal curvature. In addition, the appliance is cumbersome, and is not suitable for patients whose mouth does not open wide.

\section{Using periotomes ${ }^{33,51}$}

Periotomes are surgical instruments with a thin blade, that are inserted into the sulcus, and guided towards the root, on a slightly oblique axis, so as to progressively widen the periradicular space. The instrument is inserted around the root and continues vertically using axial pressure. A periotome is used to cut the periodontal ligament fibers, and to dilate the alveolus, but also to eliminate any suction effect by allowing air to penetrate. In most cases, the use of dental forceps is not necessary.

\section{Piezoelectric osteotomy ${ }^{10,41}$}

The basic principle of piezosurgery is to use the properties of ultrasound waves to section bone tissue, that 


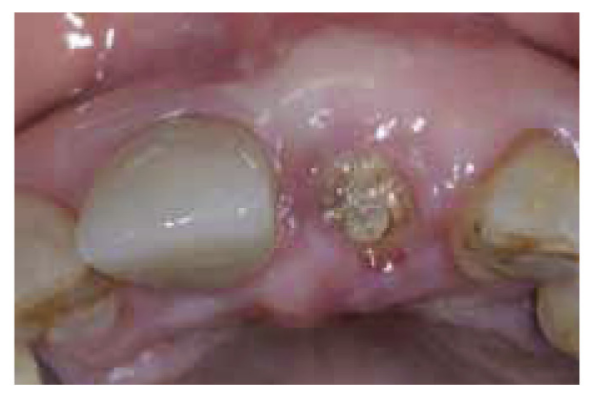

a

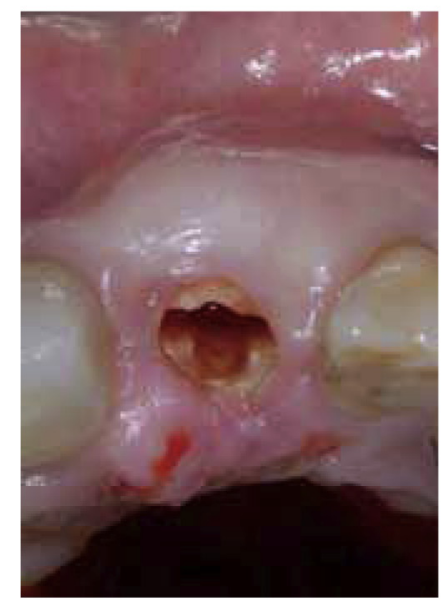

b

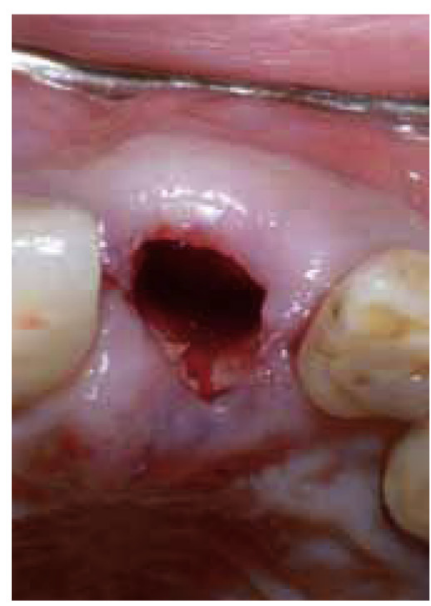

C

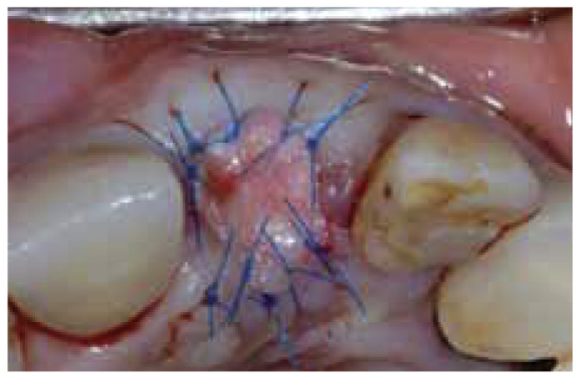

f

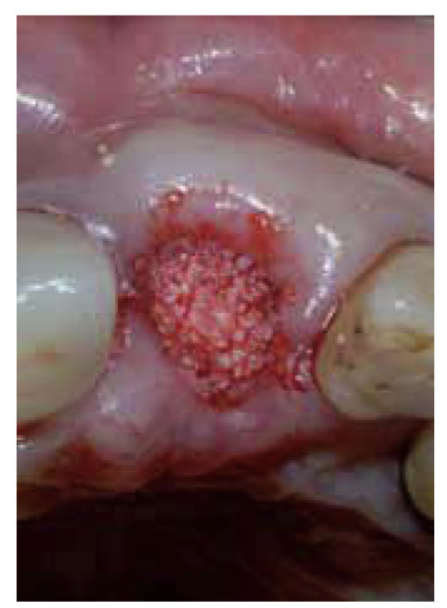

d

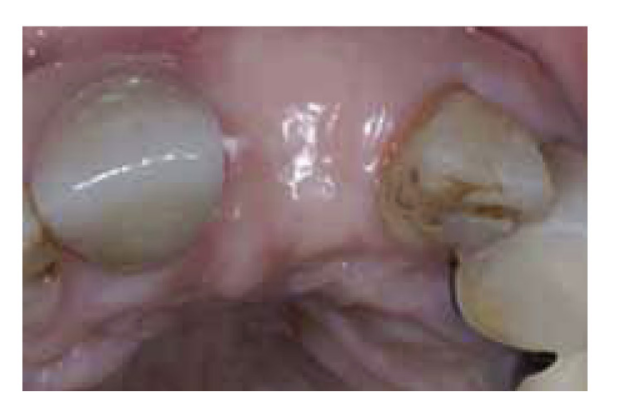

g

e

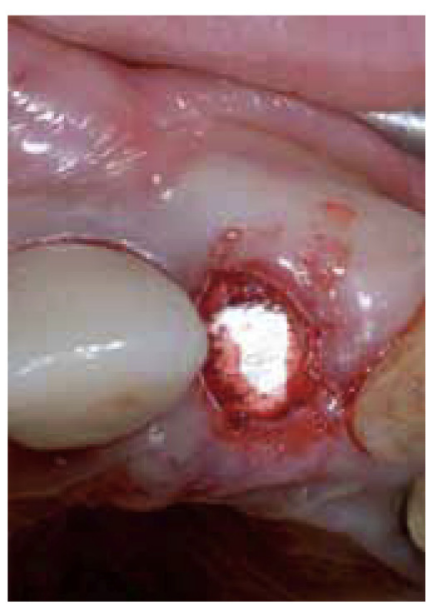

Figure 9

a) Occlusal view of the incisor to be extracted, near the root. b) Excision of the root with with ultrasound inserts (piezo-surgery). c) Empty alveolus, with preservation of the alveolus and the mucosa. d) Packing of the alveolus with Bio-Oss ${ }^{\circledR}$ small granules (Gistlich ${ }^{T M}$ ). e) $16 \times 22 \mathrm{~mm}$ resorbable membrane (BioGide ${ }^{\circledR}$, Geistlich ${ }^{T M}$ ). f) Connective graft and peripheral sutures. g) Healing at 6 weeks.

is approximately five times more powerful than other scalers.

This device features a high tension and sinus wave high frequency electric field generator. The inserts, adap- table to the type of procedure, vibrate at ultrasonic speed, in the range of 28 to $36 \mathrm{kHz}$, and make it possible to section hard tissues. The ultrasonic waves are capable of 
breaking particles into a suspension and of destroying bacterial membranes, thus helping to reduce the risk for site contamination.

It is reported that procedures carried out with piezosurgery lower the risk for post surgical trauma ${ }^{48}$.

In the case illustrated in figure 9, the extraction of a maxillary incisor, fractured at level of the alveolar ridge, was performed after sectioning of the root by using piezosurgical inserts (Fig. 9 a, b, c). An alveolectomy would have had harmful consequences for any future restoration and so, to avoid this, regeneration techniques were uti- lized not only for the hard tissues - biomaterial and membrane (Fig. $9 \mathrm{~d}, \mathrm{e}$ ), but also for the mucosal tissues, using a connective tissue graft (Fig. 9 f). The restoration of the volumes before implant therapy is very evident (Fig. $9 \mathrm{~g}$ ), in this patient with a high smile line and significant esthetic needs.

Healing may be accelerated with the use of some of the latest surgical techniques, that help promote vascularization and limit the development of necrosis. However, the outcomes are only predictable when the risk factors are under control.

\section{CONCLUSION}

Extractions may cause severe complications, and this happens, perhaps more often than we think, as some radiological studies have shown. Even though the surgical technique may be partially responsible for bone loss, other factors can also be identified.

We are not saying that practitioners should systematically use surgical techniques for regeneration, but, on the other hand, we need to be particularly attentive to risk factors related to the extraction site (extractions of mandibular incisors or of maxillary premolars), to the biotype and to the medical condition of patients (immunosupression, diabetes etc.). As orthodontists, we can try to evaluate and reduce some of the factors involved in pathologic healing, such as plaque control and the use of tobacco.

Conflicts of interest: The author declares no conflict of interest.

\section{BIBLIOGRAPHY}

1. Araujo MG, Carmagnola D, Berglundh T, Thilander B, Lindhe J. Orthodontic movement in bone defects augmented with Bio-Oss. An experimental study in dogs. J Clin Periodontol 2001;28:73-80.

2. Araujo MG, Lindhe J. Dimensional ridge alterations following tooth extraction. An experimental study in the dog. J Clin Periodontol 2005;32:212-218.

3. Artzi Z, Nemcovsky CE. The application of deproteinized bovine bone mineral for ridge preservation prior to implantation. Clinical and histological observations in a case report. J Periodontol 1998;69:1062-1067. 
4. Atwood DA. Postextraction changes in the adult mandible as illustrated by microradiographs of midsagittal sections and serial cephalometric roentgenograms. J Prosthet Dent 1963;13:810-824.

5. Atwood DA. Some clinical factors related to rate of resorption of residual ridges. 1962. J Prosthet Dent 2001;86:119-125.

6. Aydintug YS, Bayar GR, Gulses A, Misir AF, Ogretir O, Dogan N. Clinical study on the closure of extraction wounds of partially soft tissue-impacted mandibular third molars. Quintessence Int 2012;43:863-870.

7. Baldini N, De Sanctis M, Ferrari M. Deproteinized bovine bone in periodontal and implant surgery. Dent Mater 2011;27:61-70.

8. Bauerle JR. When do we treat? Chronicle 1969;33:209-210.

9. Blum IR. Contemporary views on dry socket (alveolar osteitis): a clinical appraisal of standardization, aetiopathogenesis and management: a critical review. Int J Oral Maxillofac Surg 2002;31:309-317.

10. Blus C, Szmukler-Moncler S. Atraumatic tooth extraction and immediate implant placement with Piezosurgery: evaluation of 40 sites after at least 1 year of loading. Int J Periodontics Restorative Dent 2010;30:355-363.

11. Bonine FL. Effect of chlorhexidine rinse on the incidence of dry socket in impacted mandibular third molar extraction sites. Oral Surg Oral Med Oral Pathol Oral Radiol Endod 1995;79:154-157; discussion 157-158.

12. Cardaropoli G, Araujo M, Lindhe J. Dynamics of bone tissue formation in tooth extraction sites. An experimental study in dogs. J Clin Periodontol 2003;30:809-818.

13. Cardaropoli D, Re S, Manuzzi W, Gaveglio L, Cardaropoli G. Bio-Oss collagen and orthodontic movement for the treatment of infrabony defects in the esthetic zone. Int J Periodontics Restorative Dent 2006;26:553-559.

14. Carlsson GE, Persson G. Morphologic changes of the mandible after extraction and wearing of dentures. A longitudinal, clinical, and x-ray cephalometric study covering 5 years. Odontol Rev 1967;18:27-54.

15. Cohen ME, Simecek JW. Effects of gender-related factors on the incidence of localized alveolar osteitis. Oral Surg Oral Med Oral Pathol Oral Radiol Endod 1995;79: 416-422.

16. Cox DA, Maurer T. Transforming growth factor-beta. Clin Immunol Immunopathol 1997;83:25-30.

17. de Molon RS, Avila ED, Cirelli JA, Mollo-Jr FD, Andrade MF, Barros-Filho LA. A Combined Approach for the Treatment of Resorbed Fresh Sockets Allowing Immediate Implant Restoration. A 2-Year Follow-Up. J Oral Implantol 2013.

18. Edwards JG. The prevention of relapse in extraction cases. Am J Orthod 1971;60:128-144.

19. Farina RT, Trombelli L. Wound healing of extraction sockets. Endodontic Topics 2011;25:16-43.

20. Froum S, Cho SC, Rosenberg E, Rohrer M, Tarnow D. Histological comparison of healing extraction sockets implanted with bioactive glass or demineralized freezedried bone allograft: a pilot study. J Periodontol 2002;73:94-102.

21. Graves DT, Nooh N, Gillen T, Davey M, Patel S, Cottrell D et al. IL-1 plays a critical role in oral, but not dermal, wound healing. J Immunol 2001;167:5316-5320.

22. Hammerle $\mathrm{CH}$, Araujo MG, Simion M, Osteology Consensus G. Evidence-based knowledge on the biology and treatment of extraction sockets. Clin Oral Implants Res 2012;23 Suppl 5:80-82.

23. Harder S, Egert C, Wenz HJ, Jochens A, Kern M. Influence of the drill material and method of cooling on the development of intrabony temperature during preparation of the site of an implant. Br J Oral Maxillofac Surg 2013;51:74-78.

24. Haute autorité de santé. Arrêt de la consommation de tabac : du dé pistage individuel au maintien de l'abstinence en premier recours. Recommandations de bonne pratiques 2013; Argumentation scientifique:1-559. 
25. Johnson K. A study of the dimensional changes occurring in the maxilla following tooth extraction. Aust Dent J 1969:14:241-244.

26. Kalra A, Jaggi N, Bansal M, Goel S, Medsinge SV, Abraham R et al. Comparison of rate of canine retraction into recent extraction site with and without gingival fiberotomy: a clinical study. J Contemp Dent Pract 2013;14:419-426.

27. Klammt J, Gansicke A, Gansicke W, Kunkel J, Muller U, Pingel G. [Risk of alveolitis after dental extraction]. Stomatol DDR 1985;35:586-593.

28. Kois JC, Kan JY. Predictable peri-implant gingival aesthetics: surgical and prosthodontic rationales. Pract Proced Aesthet Dent 2001;13:691-698; quiz 700, 721-692.

29. Kuboki Y, Hashimoto F, Ishibashi K. Time-dependent changes of collagen crosslinks in the socket after tooth extraction in rabbits. J Dent Res 1988;67:944-948.

30. Kylmaniemi M, Oikarinen A, Oikarinen K, Salo T. Effects of dexamethasone and cell proliferation on the expression of matrix metalloproteinases in human mucosal normal and malignant cells. J Dent Res 1996;75:919-926.

31. Lang NP, Tonetti MS. Periodontal risk assessment (PRA) for patients in supportive periodontal therapy (SPT). Oral Health Prev Dent 2003;1:7-16.

32. Lekovic V, Kenney EB, Weinlaender M, Han T, Klokkevold P, Nedic M, et al. A bone regenerative approach to alveolar ridge maintenance following tooth extraction. Report of 10 cases. J Periodontol 1997;68:563-570.

33. Levitt $D$. Atraumatic extraction and root retrieval using the periotome: a precursor to immediate placement of dental implants. Dent Today 2001;20:53-57.

34. Lodi G, Figini L, Sardella A, Carrassi A, Del Fabbro M, Furness S. Antibiotics to prevent complications following tooth extractions. Cochrane Database Syst Rev 2012;11:CD003811.

35. Lombardo L, Bragazzi R, Perissinotto C, Mirabella D, Siciliani G. Cone-beam computed tomography evaluation of periodontal and bone support loss in extraction cases. Prog Orthod 2013;14:29.

36. Murphey WH, Jr. Oxytetracycline microfluorescent comparison of orthodontic retraction into recent and healed extraction sites. Am J Orthod 1970;58:215-239.

37. Muska E, Walter $C$, Knight A, Taneja P, Bulsara Y, Hahn M, et al. Atraumatic vertical tooth extraction: a proof of principle clinical study of a novel system. Oral Surg Oral Med Oral Pathol Oral Radiol 2013;116:e303-310.

38. Nyman S, Gottlow J, Lindhe J, Karring T, Wennstrom J. New attachment formation by guided tissue regeneration. J Periodontal Res. 1987;22(3):252-4.

39. Oginni FO, Fatusi OA, Alagbe AO. A clinical evaluation of dry socket in a Nigerian teaching hospital. J Oral Maxillofac Surg 2003;61:871-876.

40. Olsson M, Lindhe J. Periodontal characteristics in individuals with varying form of the upper central incisors. J Clin Periodontol 1991;18:78-82.

41. Pavlikova G, Foltan R, Horka M, Hanzelka T, Borunska H, Sedy J. Piezosurgery in oral and maxillofacial surgery. Int J Oral Maxillofac Surg 2011;40:451-457.

42. Pinheiro ML, Moreira TC, Feres-Filho EJ. Guided bone regeneration of a pronounced gingivo-alveolar cleft due to orthodontic space closure. J Periodontol 2006;77: 1091-1095.

43. Pinho MN, Roriz VL, Novaes AB, Jr., Taba M, Jr., Grisi MF, de Souza SL. Titanium membranes in prevention of alveolar collapse after tooth extraction. Implant Dent 2006;15:53-61.

44. Reichert C, Wenghofer M, Gotz W, Jager A. Pilot study on orthodontic space closure after guided bone regeneration. J Orofac Orthop 2011;72:45-50.

45. Rivera Circuns AL, Tulloch JF. Gingival invagination in extraction sites of orthodontic patients: their incidence, effects on periodontal health, and orthodontic treatment. Am J Orthod 1983;83:469-476.

46. Robertson PB, Schultz LD, Levy BM. Occurrence and distribution of interdental gingival clefts following orthodontic movement into bicuspid extraction sites. J Periodontol 1977;48:232-235. 
47. Saund D, Dietrich T. Minimally-invasive tooth extraction: doorknobs and strings revisited! Dent Update 2013;40:325-326, 328-330.

48. Sivolella S, Berengo M, Bressan E, Di Fiore A, Stellini E. Osteotomy for lower third molar germectomy: randomized prospective crossover clinical study comparing piezosurgery and conventional rotatory osteotomy. J Oral Maxillofac Surg 2011;69:e15-23.

49. Tallgren $A$. The continuing reduction of the residual alveolar ridges in complete denture wearers: a mixedlongitudinal study covering 25 years. J Prosthet Dent 1972;27:120-132.

50. Ten Heggeler JM, Slot DE, Van der Weijden GA. Effect of socket preservation therapies following tooth extraction in non-molar regions in humans: a systematic review. Clin Oral Implants Res 2011;22:779-788.

51. Thomson PJ. Minimising trauma in dental extractions: the use of the periotome. Br Dent J 1992;172:179.

52. Ulm C, Solar P, Blahout R, Matejka M, Gruber H. Reduction of the compact and cancellous bone substances of the edentulous mandible caused by resorption. Oral Surg Oral Med Oral Pathol 1992;74:131-136.

53. Van der Weijden F, Dell'Acqua F, Slot DE. Alveolar bone dimensional changes of post-extraction sockets in humans: a systematic review. J Clin Periodontol 2009;36:1048-1058.

54. Vergara JA, Caffesse RG. Preservation of esthetics with implant dentistry: a clinical report. Clin Implant Dent Relat Res 2002;4:200-211.

55. Vignoletti F, Matesanz P, Rodrigo D, Figuero E, Martin C, Sanz M. Surgical protocols for ridge preservation after tooth extraction. A systematic review. Clin Oral Implants Res 2012;23 Suppl 5:22-38.

56. Vittorini Orgeas G, Clementini M, De Risi V, de Sanctis M. Surgical techniques for alveolar socket preservation: a systematic review. Int J Oral Maxillofac Implants 2013;28:1049-1061.

57. Wehrbein H, Bauer W, Diedrich PR. Gingival invagination area after space closure: a histologic study. Am J Orthod Dentofacial Orthop 1995;108:593-598.

58. Weiss A, Stern A, Dym H. Technological advances in extraction techniques and outpatient oral surgery. Dent Clin North Am 2011;55:501-513.

59. Yamano S, Kuo WP, Sukotjo C. Downregulated gene expression of TGF-beta in diabetic oral wound healing. J Craniomaxillofac Surg 2013;41:e42-48.

60. Zubillaga G, Von Hagen S, Simon BI, Deasy MJ. Changes in alveolar bone height and width following post-extraction ridge augmentation using a fixed bioabsorbable membrane and demineralized freeze-dried bone osteoinductive graft. J Periodontol 2003;74:965-975. 